\author{
Dušan Koval ${ }^{1}$ \\ Jean-Marc Busnel ${ }^{2,3}$ \\ Jan Hlaváček ${ }^{1}$ \\ Jiří Jiráček ${ }^{1}$ \\ Václav Kašička ${ }^{1}$ \\ Gabriel Peltre ${ }^{2}$ \\ ${ }^{1}$ Institute of Organic Chemistry \\ and Biochemistry, \\ Academy of Sciences \\ of the Czech Republic, Prague \\ Czech Republic \\ ${ }^{2}$ Laboratoire Environnement et \\ Chimie and Analytique, Ecole \\ Supérieure de Physique et \\ Chimie Industrielles, Paris, \\ France \\ ${ }^{3}$ Laboratoire d'Electrochimie \\ Physique et Analytique, Ecole \\ Polytechnique Fédérale de \\ Lausanne, Lausanne, \\ Switzerland
}

Received March 25, 2008

Revised June 12, 2008

Accepted June 12, 2008
Research Article

\section{Evaluation of carrier ampholyte-based capillary electrophoresis for separation of peptides and peptide mimetics}

\begin{abstract}
Carrier ampholyte-based capillary electrophoresis (CABCE) has recently been introduced as an alternative to CE (CZE) in the classical buffers. In this study, isoelectric BGEs were obtained by fractionation of Servalyt $\mathrm{pH} 4-9$ carrier ampholytes to cuts of typical width of $0.2 \mathrm{pH}$ unit. CABCE feasibility was examined on a series of insect oostatic peptides, i.e. proline-rich di- to decapeptides, and phosphinic pseudopeptides - tetrapeptide mimetics synthesized as a mixture of four diastereomers having the $-\mathrm{P}(\mathrm{O})(\mathrm{OH})-\mathrm{CH}_{2}-$ moiety embedded into the peptide backbone. With identical selectivity, the separation efficiency of CABCE proved to be as good as classical CE for the insect oostatic peptides and better for diastereomers of the phosphinic pseudopeptides. In addition, despite the numerous species present in the narrow $\mathrm{pH}$ cuts of carrier ampholytes, CABCE seems to be free of system zones that could hamper the analysis. Peak symmetry was good for moderately to low mobile peptides, whereas some peak distortion due to electromigration dispersion, was observed for short peptides of rather high mobility.
\end{abstract}

Keywords:

CABCE / Insect oostatic peptides / Isoelectric background electrolyte / Phosphinic pseudopeptides / System zones

DOI 10.1002/elps.200800193

\section{Introduction}

The interest in isoelectric buffers in CE (CZE) results from their obvious inherent advantage - low conductivity. High electric field strength can then be applied along the capillary without detrimental peak broadening effect due to Joule heating $[1,2]$. Consequently, the analysis time can be remarkably shortened. The principal way to isoelectric buffers is via single amphoteric compounds with welldefined structure and isoelectric point $(\mathrm{p} I)$. To be a "good ampholyte" (in the sense of a good constituent of BGE in $\mathrm{CE})$, the compound should have a distinct $\mathrm{p} I$ and a moderate buffering capacity, i.e. it should follow Svensson's (Rilbe's) rule saying that $|\mathrm{pKa}-\mathrm{pI}|<1$ [3, 4]. Examples of such compounds are iminodiacetic acid, glutamic acid, aspartic acid or lysine. In general, limited number of appropriate ampholytes is, however, commercially available leaving

Correspondence: Dr. Václav Kašička, Institute of Organic Chemistry and Biochemistry, v.v.i., Academy of Sciences of the Czech Republic, Flemingovo nam. 2, 16610 Prague 6, Czech Republic E-mail: kasicka@uochb.cas.cz

Fax: +420-220-183-592

Abbreviations: CAs, carrier ampholytes; CABCE, carrier ampholyte-based capillary electrophoresis; HPC, hydroxypropylcellulose; IOPs, insect oostatic peptides; PPs, phosphinic pseudopeptides a gap in the 5-7 $\mathrm{pH}$ region. This kind of problems induced synthesis of carrier ampholytes (CAs) by Vesterberg in 1960s [4, 5]. Since that, CAs are broadly used as BGE constituents creating a $\mathrm{pH}$ gradient in IEF. Some groups, however, choose the direct route by a synthesis of novel ampholytes with desired $\mathrm{pI}$ values [6-8].

Narrow pH cuts of CAs are an alternative approach to isoelectric (also called quasi-isoelectric by some authors [9]) buffers. The CAs fractions of typical width of $0.1-0.2 \mathrm{pH}$ unit can be prepared by preparative IEF, e.g. in a thick granulated gel made of Sephadex beads [10] or in a Rotofor apparatus [9]. Rather laborious preparative work is paid off by the continuity in $\mathrm{pH}$ of the fractions which surpasses uneven $\mathrm{pI}$ distribution of the single ampholytes and, therefore, allows CE experiments in full $\mathrm{pH}$ range of CAs. On the other hand, due to proprietary composition of commercial CAs, the knowledge of number and structures of individual ampholytes remains limited. Early estimation ranged from 360 to more than enormous 6000 species in the 3-10 pH CAs [11]. More rational estimation based on CE analysis leads to more than 700 species [12]. Finally, commercial CAs were fractionated and analyzed by CE-MS in acidic formate BGE to reveal total number of $\sim 300$ compounds in Ampholine, $\sim 250$ in Bio-Lyte, $\sim 650$ in Pharmalyte and $\sim 700$ in Servalyt broad $\mathrm{pH}$ range CAs. In addition, total number of isoforms was determined as $\sim 1200$ in Ampholine, 1200 in Bio-Lyte, 2200 in Pharmalyte and $\sim 3900$ in Servalyt CAs [13]. In addition, the 
number of CAs possessing a $\mathrm{p} I$ value in a given $\mathrm{pH}$ range turned out to vary with $\mathrm{pH}$, with significantly less species in the alkaline region [14]. Apart from "good" ampholytes, many CA fractions contain some species ("poor" ampholytes with "diffuse" $\mathrm{p} I$ ), which do not possess the focusing ability.

Nevertheless, for CA-based capillary electrophoresis (CABCE), this is no disruptive news. CA narrow $\mathrm{pH}$ cuts were acknowledged to have sufficient buffering [10] and loading capacity [15] and proved well as BGEs in CABCE for separation of proteins $[9,12]$ and peptides $[16,17]$. Still, low conductive CAs fractions were introduced as trailing ions in transient ITP preconcentration of proteins [18].

This paper aims to expand the CABCE knowledge in two ways. Firstly, CABCE performance has been so far demonstrated mostly on few acidic and alkaline CAs fractions. Herein, we evaluated the efficiency of CABCE for the separation of diastereomers of phosphinic pseudopeptides (PPs) and a series of proline-rich insect oostatic peptides (IOPs) in a broad $\mathrm{pH}$ range. Then, a study on peak symmetry and system peaks in CABCE is provided, which has not been much discussed so far.

To briefly introduce the testing compounds, PPs were discovered as potent inhibitors of human metalloenzyme betaine: homocysteine $S$-methyltransferase few years ago [19]. A series of the PPs having incorporated the phosphinate moiety $-\mathrm{P}(\mathrm{O})(\mathrm{OH})-\mathrm{CH}_{2}$ - into the peptidic backbone were synthesized as a mixture of four diastereomers. Electrophoretic characterization [20-22] and challenging separation of the diastereomers by CZE $[22,23]$ were the subjects of our earlier papers. Further, praline-rich IOPs were designed as antigonadotropic insect hormones with potential use as biodegradable insecticides [24-26]. Homology series of oostatic di- to decapeptides were recently characterized by CZE [27] and CEC [28]. As such, separation of the IOPs and diastereomers of the PPs was used as a model for evaluation of CABCE properties.

\section{Materials and methods}

\subsection{Chemicals and CA-based BGEs}

All chemicals were of analytical reagent grade. Phosphoric acid, formic acid, acetic acid, sodium hydroxide and DMSO were obtained from Lachema (Brno, Czech Republic). MES, MOPS, tricine ( $N$-[tris(hydroxymethyl)methyl]glycine), morpholine and 2-amino-2-methyl-1-propanol were supplied by Serva (Heidelberg, Germany). Tris was from Merck (Darmstadt, Germany).

The CA-based BGEs were prepared according to a previously described procedure [10]. Briefly, a wide $\mathrm{pH}$ range CAs, Servalyt pH 4-9 (Coger, Paris, France), were 1:1 diluted with water and subjected to preparative IEF in a granulated gel made of Sephadex G-25 beads. After the focusing, the gel was manually cut into 30 fractions and the fractionated CAs were simply eluted from the gel by distilled water percolation. Following the different dilutions that have been performed throughout the CAs fractionation, each CA narrow $\mathrm{pH}$ cut of average $0.2 \mathrm{pH}$ width contained ca. $10 \% \mathrm{~m} / \mathrm{v}$ of CAs. These CA fraction stock solutions were then diluted with distilled water and used as BGEs in CABCE. It should be noted that $\mathrm{v} / \mathrm{v}$ concentration of BGEs refers to dilution of the stock CA fractions and not to original Servalyt $\mathrm{pH} 4-9$.

\subsection{Analyzed compounds}

PPs were synthesized as a mixture of four diastereomers on a Rink Amide AM resin or 2-chlorotrityl resin as reported in $[19,29]$ using the protected PP precursors Fmoc-Ala $\psi\left[\mathrm{PO}(\mathrm{OAd})-\mathrm{CH}_{2}\right] \mathrm{Leu}-\mathrm{OH}$, Fmoc-Phe $\psi[\mathrm{PO}(\mathrm{OAd})-$ $\left.\mathrm{CH}_{2}\right] \mathrm{Leu}-\mathrm{OH}$ and Fmoc-Phe $\psi\left[\mathrm{PO}(\mathrm{OAd})-\mathrm{CH}_{2}\right] \mathrm{Ala}-\mathrm{OH}$. The individual diastereomers were preparatively separated by HPLC and used for evaluation of the migration order of<smiles>CC(=O)N[C@@H](C(=O)N[C@@H](C)P(=O)(O)C[C@@H](CC(C)C)C(=O)N[C@@H]([SiH3])C(N)=O)C(C)C</smiles>

VH<smiles>CC(=O)N[C@@H](C(=O)N[C@@H](Cc1ccccc1)CP(=O)(O)C[C@@H](CC(C)C)C(=O)N[C@@H](Cc1c[nH]cn1)C(N)=O)C(C)C</smiles>

VHA<smiles>CC(=O)N[C@@H](C)C(=O)N[C@@H](Cc1ccccc1)P(=O)(O)C[C@@H](C)C(=O)N[C@@H]([Si])C(N)=O</smiles>

VHB

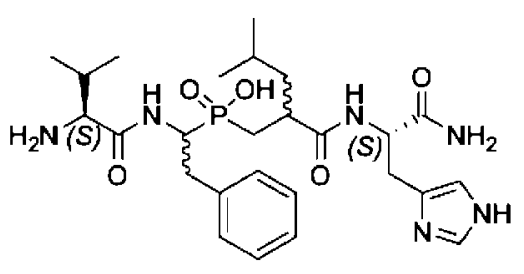

NVHA

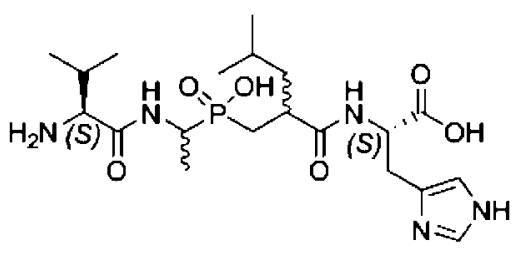

NVHO

Figure 1. Molecular structures of analyzed PPs. Configurations on the chiral centers are indicated by wedged bonds or by wavy bonds for variable orientation of the substituents. 
the diastereomers by spiked injection. The structures of the PPs are provided in Fig. 1.

IOPs were synthesized as described in [24, 26]. Di-, tri-, and tetrapeptides were prepared by stepwise synthesis in solution. Larger peptides were obtained by a solidphase approach on polystyrene/divinylbenzene resin with 2-chlortrityl linker using the Fmoc/tBu strategy. For the sequences of the IOPs, see Table 1.

\subsection{Instrumentation}

CABCE experiments were carried out using an $\mathrm{HP}^{3 \mathrm{D}} \mathrm{CE}$ apparatus (Agilent, Waldbronn, Germany), analyses of the IOPs in the classical buffers were performed in a P/ACE MDQ analyzer (Beckman-Coulter, Fullerton, CA, USA) and a home-made CE apparatus [30] was used for analyses of the PPs in the classical buffers. Analytes were detected by their UV absorbance at $214 \mathrm{~nm}$ in CABCE experiments and at $206 \mathrm{~nm}$ in the classical buffers. Evaluation of all the data records was performed using the Clarity chromatography station (DataApex, Prague, Czech Republic) in order to standardize the calculation procedure. Fused silica capillaries of $50 / 370 \mu \mathrm{m}$ id/od were supplied by Polymicro Technologies (Phoenix, AZ, USA). Permanent capillary coatings by hydroxypropylcellulose (HPC) and polyacrylamide were performed according to Shen and Smith [31], and our previous paper [32], respectively. Between subsequent separations in the same BGE, only a BGE rinse was performed (100 kPa, $2 \mathrm{~min})$. Water and the new BGE were

Table 1. Analyzed insect oostatic peptides (IOPs)

\begin{tabular}{|c|c|c|c|}
\hline Peptide no. & Sequence & & $\mathrm{M}_{\mathrm{r}}$ \\
\hline 2 & YD & $\mathrm{H}$-Tyr-Asp-OH & 296.3 \\
\hline 3 & YDP & H-Tyr-Asp-Pro-OH & 393.4 \\
\hline 4 & YDPA & H-Tyr-Asp-Pro-Ala-OH & 464.5 \\
\hline 5 & YDPAP & H-Tyr-Asp-Pro-Ala-Pro-OH & 561.6 \\
\hline 6 & $\mathrm{YDPAP}_{2}$ & $\mathrm{H}$-Tyr-Asp-Pro-Ala-(Pro) ${ }_{2}-\mathrm{OH}$ & 658.7 \\
\hline 7 & $\mathrm{YDPAP}_{3}$ & H-Tyr-Asp-Pro-Ala-(Pro) ${ }_{3}-\mathrm{OH}$ & 755.8 \\
\hline 8 & $\mathrm{YDPAP}_{4}$ & H-Tyr-Asp-Pro-Ala-(Pro) ${ }_{4}-\mathrm{OH}$ & 852.9 \\
\hline 9 & YDPAP $_{5}$ & $\mathrm{H}$-Tyr-Asp-Pro-Ala-(Pro) $)_{5}-\mathrm{OH}$ & 950.0 \\
\hline 10 & $\mathrm{YDPAP}_{6}$ & H-Tyr-Asp-Pro-Ala-(Pro) $6-\mathrm{OH}$ & 1044.1 \\
\hline
\end{tabular}

successively flushed through the capillary whenever different BGEs were used in the same capillary. Water solutions of the PPs $(0.7-2.5 \mathrm{mM})$ and the IOPs $(0.05-0.5 \mathrm{mg} / \mathrm{mL})$ were introduced into the capillary hydrodynamically (for details, see description of the figures).

\section{Results and discussion}

\subsection{Separation performance of CABCE}

\subsubsection{Phosphinic pseudopeptides}

Separation of diastereomers of the PPs was selected as a model problem for testing suitability of CABCE for highperformance separations. A strategy used for synthesis of PPs provided four diasteromers of each compound. Due to small differences in charge to size ratio, separation of the diastereomers is challenging in CZE. Extensive research revealed that separation of diastereomers of the PPs occurs due to small variations in acidity (ionization) constants (pKa) of acidic and basic functions in their molecules. Consequently, $\mathrm{pH}$ of the $\mathrm{BGE}$ is a major selectivity parameter. As can be seen in Fig. 1, four types of ionizable groups can be distinguished in the pseudopeptide structures: the phosphinic acid group (pKa 1.5-2.25), C-terminal carboxylic groups (pKa 2.94-3.50), imidazolyl moiety of histidine (6.55-8.32) and N-terminal amino groups (pKa 7.65-8.28) (for pKa determination see [21, 22]).

In general, the optimum $\mathrm{pH}$ interval for $\mathrm{CE}$ separation of pseudopeptide diastereomers lies in acidic $\mathrm{pH}$ region of 1.4-2.8 close to $\mathrm{pKa}$ values of central phosphinic acid moiety [23]. Additionally, diastereomers of the PPs listed in Fig. 1 can be separated within the 3-9 $\mathrm{pH}$ interval wherein CAs narrow $\mathrm{pH}$ cuts are available [22]. CABCE optimization revealed that separation of the diastereomers takes place at $\mathrm{pH}$ values very close to those at which they were separated by CZE in classical BGEs. Overall results are summarized in Table 2, selected CABCE electropherograms are in Fig. 2 and for CE separations in the classical BGEs, see our previous papers [21, 22]. Migration order of individual diastereomers in the classical and CA-based BGEs was identical for all of the PPs as determined by a spiked injection of the single isomers. Thus, in spite of qualitatively

Table 2. Separation of diastereomers of the PPs-a comparison of the CA-based and the classical salt-based BGEs

\begin{tabular}{|c|c|c|c|c|c|c|c|c|c|c|c|}
\hline Peptide & $\begin{array}{l}\text { Ionic } \\
\text { form }\end{array}$ & BGE & $\mathrm{pH}$ & $\begin{array}{l}\text { Separ. } \\
\text { peaks }\end{array}$ & Min. resol. & Avg. resol. & BGE & $\mathrm{pH}$ & $\begin{array}{l}\text { Separ. } \\
\text { peaks }\end{array}$ & Min. resol. & Avg. resol. \\
\hline NVHO & + & Fr. $5,25 \%$ & 3.2 & 4 & 2.96 & 6.95 & $25 \mathrm{mM}$ Tris-formic acid & 3.0 & 4 & 1.68 & 3.28 \\
\hline NVHA & + & Fr. $18,10 \%$ & 6.9 & 4 & 1.83 & 2.54 & $40 \mathrm{mM} \mathrm{NaOH}-\mathrm{MES}$ & 6.5 & 4 & 1.58 & 2.43 \\
\hline VH & - & Fr. $19,25 \%$ & 7.1 & 4 & 0.68 & 4.92 & $40 \mathrm{mM} \mathrm{NaOH}-\mathrm{H}_{3} \mathrm{PO}_{4}$ & 7.0 & 2 & 0 & 1.56 \\
\hline VHA & - & Fr. $19,25 \%$ & 7.1 & 4 & 1.40 & 6.51 & $40 \mathrm{mM} \mathrm{NaOH}-\mathrm{H}_{3} \mathrm{PO}_{4}$ & 7.0 & 3 & 0 & 2.63 \\
\hline VHB & - & Fr. $19,25 \%$ & 7.1 & 4 & 0.59 & 4.60 & $40 \mathrm{mM} \mathrm{NaOH}-\mathrm{H}_{3} \mathrm{PO}_{4}$ & 7.0 & 3 & 0 & 1.81 \\
\hline NVHA & - & Fr. $24,20 \%$ & 8.0 & 4 & 1.35 & 6.62 & $40 \mathrm{mM} \mathrm{NaOH}-\mathrm{H}_{3} \mathrm{PO}_{4}$ & 7.7 & 4 & 2.11 & 6.65 \\
\hline NVHO & - & Fr. $24,20 \%$ & 8.0 & 4 & 1.69 & 2.64 & $25 \mathrm{mM} \mathrm{NaOH}$-tricine & 7.8 & 4 & 2.15 & 4.49 \\
\hline
\end{tabular}



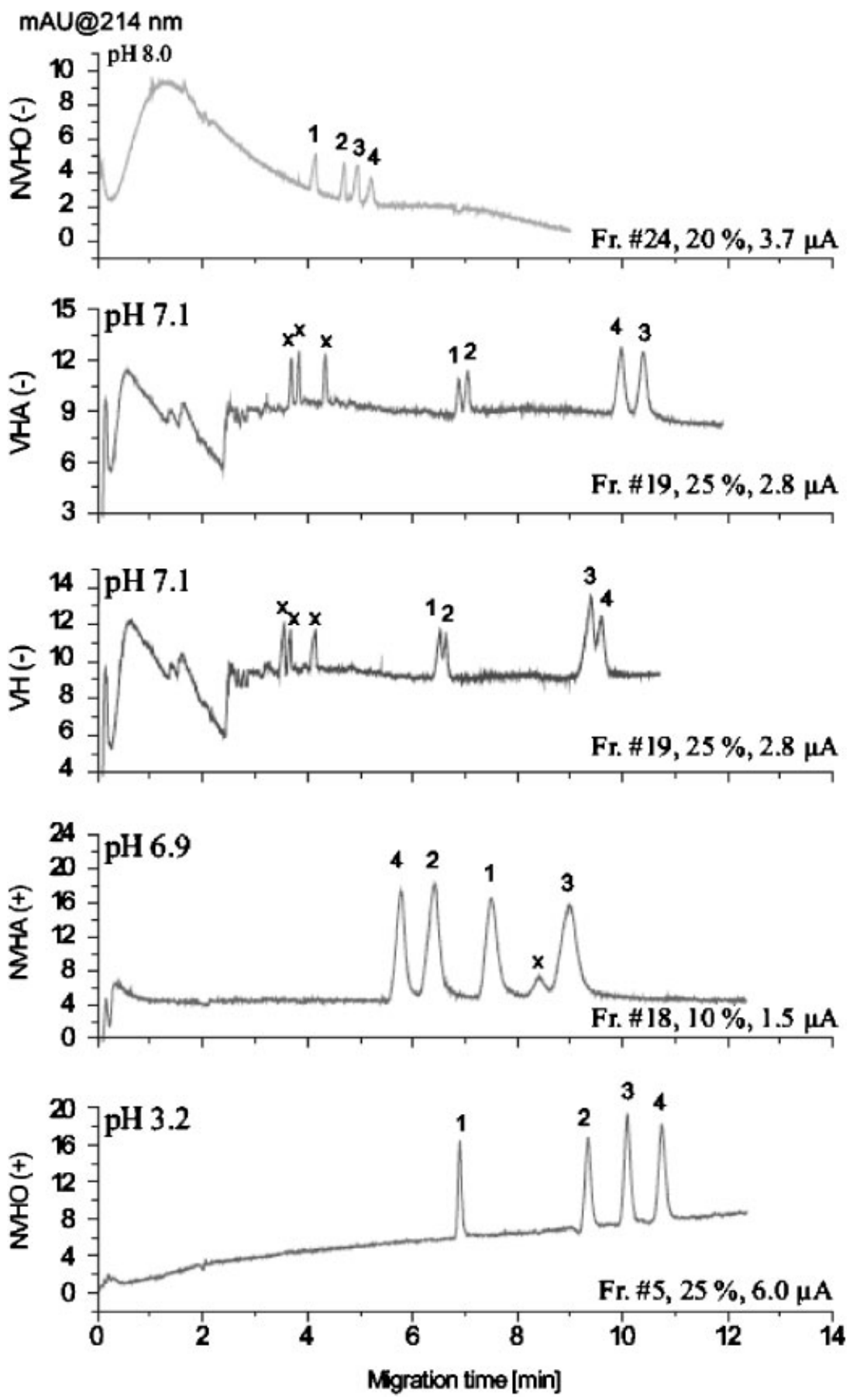

Figure 2. CE separation of diastereomers of the PPs in the CA-based BGEs. Experimental conditions: capillary, HPC-coated, effective/total length $26.5 / 35 \mathrm{~cm} \times 50 \mu \mathrm{m} \quad$ id; BGEs, CA narrow pH cuts, $\mathrm{pH}$, the fraction number and the $\mathrm{v} / \mathrm{v}$ arbitrary concentration are indicated in the figure; voltage $\pm 30 \mathrm{kV}$ according to the analyte net charge; current, indicated in the figure; sample, PPs (see Fig. 1) in water, $0.7-3.7 \mathrm{mM}$ overall concentration; injection, $30 \mathrm{mbar}, 5 \mathrm{~s}$; detection, UVabsorption at $214 \mathrm{~nm}$; temperature, $25^{\circ} \mathrm{C}$ Diastereomers are individually numbered according to their effective mobilities at $\mathrm{pH}$ $2 ; x$-sample impurities. different composition, the CA-based BGEs possess the same selectivity for these analytes as classical BGEs. In average, CABCE provided resolution factors of the same magnitude as CE in the classical BGEs. Nevertheless, separation of the four diastereomers of VH, VHA and VHB was successful only in CABCE (see Table 2). It should be noted that the separation capabilities of both types of BGEs are presented at the optimized experimental conditions for each type of these BGEs, not at exactly the same conditions, see, e.g. small differences in $\mathrm{pH}$ of classical BGEs and CA-based
BGEs in Table 2. Our preliminary experiments have shown that the separations of diastereomers of PPs in classical BGEs with more mobile (conductive) sodium cation were more efficient than those with less mobile (conductive) Tris cation. For that reason the BGEs with sodium cation were mostly used for comparison with CA-based BGEs (see Table 2). The separation capability was evaluated according to minimum and/or average resolution of the analytes, which is a decisive parameter of the fruitfulness of the separation method. 
In addition to $\mathrm{pH}$, concentration of the CA fractions can also be varied in order to improve the separation [32]. Resolution of diastereomers of the PPs was investigated in the $10-25 \% \mathrm{v} / \mathrm{v}$ interval of the arbitrary concentration of the CA fractions. It turned out that higher concentration has a positive effect on the resolution, however, at the expense of higher conductivity of the BGE and decreased sensitivity of the UV detection due to increased baseline signal of highly concentrated CAs. Typically, 20-25\%v/v CA-based BGEs were employed. Similarly to the classical BGEs, the increased separation power of the more concentrated CA-based BGEs can be attributed to their enhanced buffering capacity and reduced electromigration dispersion.

\subsubsection{Insect oostatic peptides}

A systematic characterization of the CA narrow $\mathrm{pH}$ cuts has already been performed by means of buffering capacity, conductivity and composition heterogeneity [10]. In the same paper, proteins of a Dactylis glomerata pollen extract were separated by the gel electrotitration curve technique in a 3-10 $\mathrm{pH}$ gradient formed by Servalyt CAs. However, performance of the CABCE was typically studied only for few acidic and alkaline fractions. Herein, CABCE was evaluated in a much broader $\mathrm{pH}$ range by using a series of IOPs as model compounds. Electromigration properties of the IOPs can be easily estimated from their molecular structures (see Table 1). The consequence of the presence of C-terminal carboxyl, lateral aspartate carboxyl and $\mathrm{N}$-terminal amino groups in each peptide is their net anionic charge in the 4-9 $\mathrm{pH}$ region applicable in CABCE. Moreover, the IOPs migrate in a constant order in BGEs of $\mathrm{pH} 5.5$ and higher because the carboxylic groups are fully deprotonated and mobilities are proportional to the molar mass increment in a series of the IOPs homologs (see Figs. 3 and 4).

On the other hand, migration order of the IOPs was variable in the $4.5-5.5 \mathrm{pH}$ interval. In this $\mathrm{pH}$ region, the carboxyl groups in the peptides were not completely dissociated but, importantly, $\mathrm{pKa}$ values of these groups differ between the peptides and depend on peptide sequence. Such variations in $\mathrm{pKa}$ are presumably responsible for variable migration order of the short peptides YD, YDP and YDPA in the 4.5-5.5 pH interval (data not shown).

Hence, the migration order of the IOPs remains constant from $\mathrm{pH} \mathrm{5.5}$, but the resolution of the peptides is $\mathrm{pH}$ dependent. As can be seen in Table 3, a local maximum of the resolution can be distinguished at pH 6.7 (CA fraction \#17) with the lowest resolution factor between all peaks equal to 1.78. A further increase of $\mathrm{pH}$ to 7.5 (CA fraction $\# 22$ ) leads to a slump of resolution between the peaks of YDP and YDPA down to 0.55 (see Fig. 3, peak nos. 3 and 4). The best CABCE separation of the IOPs was, however, obtained in the most alkaline CA fraction $\$ 29$ of $\mathrm{pH} 9.1$ with the lowest resolution factor equal to 1.99 .

For comparison, identical set of IOPs was analyzed in conventional salt-based BGEs of a moderate 20-25 mM ionic strength. In general, similar $\mathrm{pH}$ dependence of resolution of the peptides was achieved (see Fig. 4 and Table 4). Excellent efficiency of a Na-MES, pH 6.3, BGE is followed by slight deterioration in Na-MOPS, pH 7.2, BGE. Further, resolution in a morpholine-acetate, $\mathrm{pH}$ 8.7 BGE was not as good as in its CA-based counterpart (see Figs. 3 and 4, and Tables 3 and 4).

\subsection{System zones and electromigration dispersion in CABCE}

Despite of being used for several decades, exact composition of CAs remains undisclosed in terms of exact chemical constitution and $\mathrm{pH}$ distribution of individual species. Thanks to recent work of Righetti's group, we now know that the Servalyt $\mathrm{pH}$ cuts of $0.2 \mathrm{pH}$ width comprise $\sim 13$ compounds and $\sim 87$ isoforms in acidic fractions and as low as $\sim 4$ compounds and $\sim 20$ isoforms in alkaline fractions [13]. Such a heterogeneity and amphoteric character make CAs very different from the classical BGEs that typically consist of limited number of well-defined ionic constituents. For instance, effect of the BGE concentration on electrophoretic mobility of the analyte is frequently described as a function of ionic strength of the BGE [32]. Similarly, different classical BGEs can be compared if effective mobilities of the analytes are compared at the same ionic strength, $\mathrm{pH}$ and temperature of the BGE [33]. In CABCE, ionic strength can hardly be used as a standardized concentration function. Due to amphoteric character of CAs, values of ionic strength, when calculated as for saltbased BGEs, would be rather low for CAs concentrations commonly used in CABCE and would imply low loading capacity (maximum analyte concentration or sample amount separable under given experimental conditions). However, it was found that loading capacities of some narrow pH CA cuts (typical conc. $10 \% \mathrm{v} / \mathrm{v}$ ) were equivalent to about $60 \mathrm{mM}$ ionic strength of the classical ammediolchromate BGE [15]. Hence, only limited conclusions can be drawn from comparison of electrophoretic mobilities of the IOPs in CA-based and classical BGEs. Accordingly, no significant difference in electrophoretic mobilities of the IOPs was found between the narrow CAs cuts of nominal concentration $20 \% \mathrm{v} / \mathrm{v}$ and the salt-based BGE of $20-25 \mathrm{mM}$ ionic strength. Further, migration order of all the peptides was identical in both types of BGEs. Therefore, we assume that $\mathrm{CABCE}$ can provide as good separation results for peptide separations and analyses as CE (CZE) in the classical BGEs can do.

Electromigration dispersion of the analyte zone is a crucial factor in seeking for high separation efficiency and peak resolution. Formation of system zones and ability of BGEs to provide symmetrical peaks of the analytes can be nowadays easily inspected by Peakmaster software developed by Gaš's group (www.natur.cuni.cz/gas). According to the theory of system peaks and electromigration dispersion in CE outlined by this group in recent years [34-37], total 


\section{mAU@214 nm}
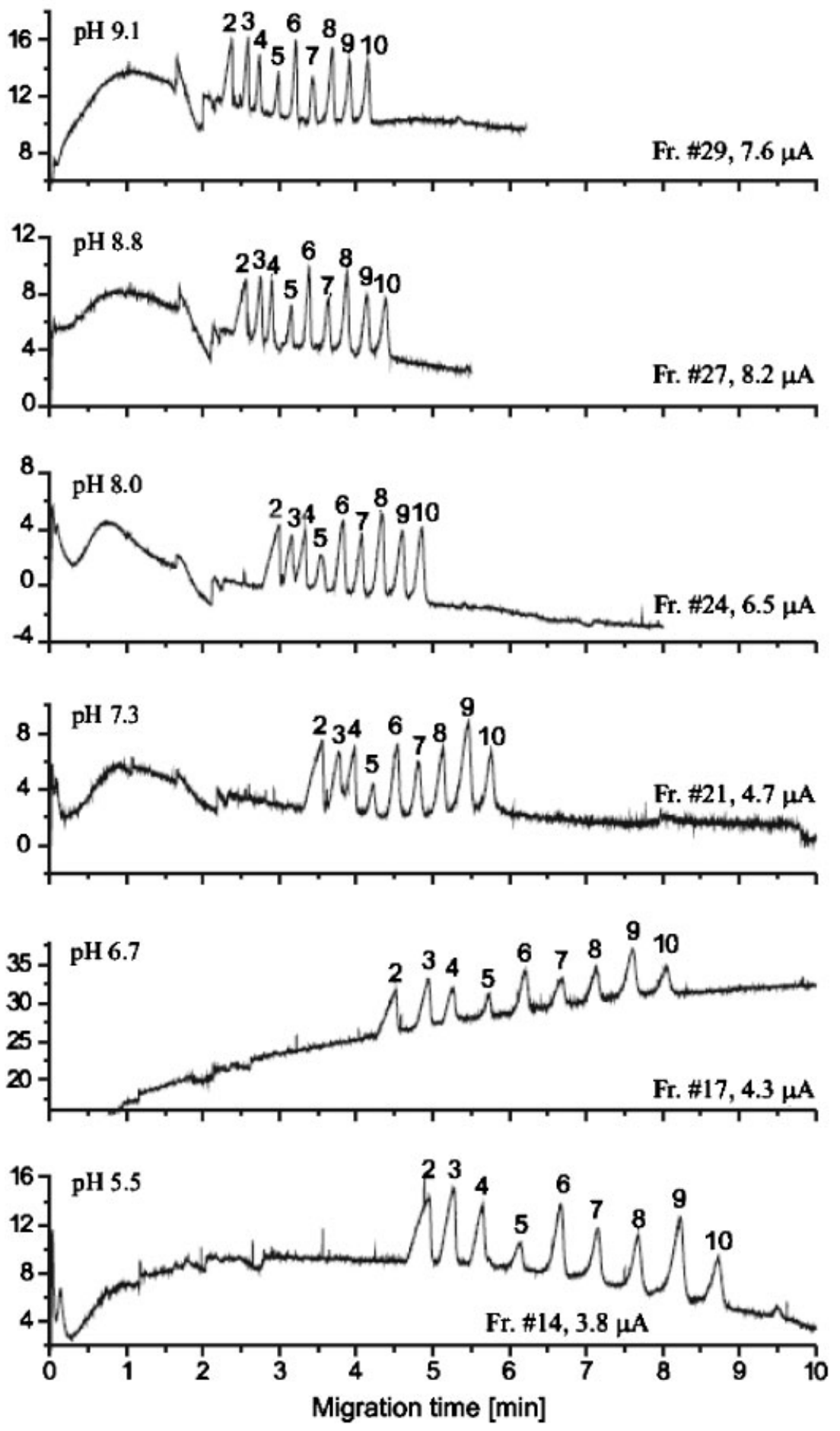

Figure 3. CE separation of a series of the IOPs in the CA-based BGEs. Experimental conditions: capillary, HPC-coated, effective/ total length $31.5 / 40 \mathrm{~cm} \times 50 \mu \mathrm{m}$ id; BGEs, CA narrow $\mathrm{pH}$ cuts, $20 \% \mathrm{v} / \mathrm{v}, \mathrm{pH}$ and the fraction number are indicated in the figure; voltage, $-30 \mathrm{kV}$; current, as indicated in the figure; sample, a mixture of the IOPs in water, $0.05-0.5 \mathrm{mg} / \mathrm{mL}$ each; injection $30 \mathrm{mbar}, 5 \mathrm{~s}$; detection, UV at $214 \mathrm{~nm}$; temperature, $25^{\circ} \mathrm{C}$. Peak identification: 2, YD; 3, YDP; 4, YDPA 5-10, YDPA $(P)_{1}-\mathrm{YDPA}(\mathrm{P})_{6}$. number of the system zones is equal to total number of electrically charged species present within the separation space. Consequently, since the CAs cuts consist of up to tens of ampholytes, the corresponding number of system zones would be formed in the capillary, which would completely destroy the electropherograms. This is, however, not the case as can be evidenced by lots of successful CABCE separations. Peakmaster simulations of a simplified narrow $\mathrm{pH}$ CA cuts reveals that mobilities of the system zones induced by the CA species are very low; the lower the CA 


\section{mAU@206 nm}
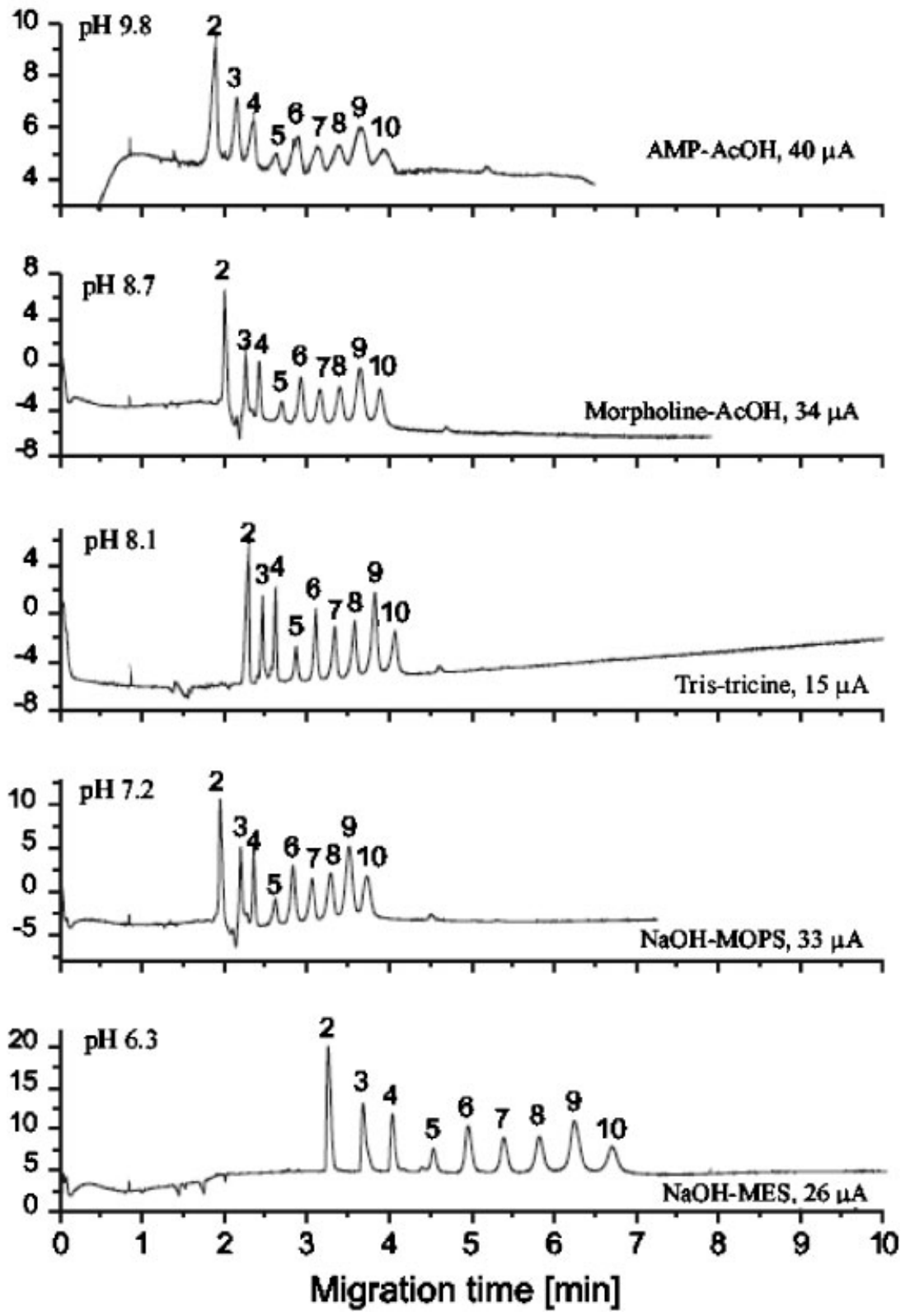

Figure 4. CE separation of a series of the IOPs in the classical salt-based BGEs. Experimental conditions: capillary, polyacrylamide-coated, effective/total length $20.7 / 31.0 \mathrm{~cm} \times 50 \mu \mathrm{m} \quad$ id; BGEs, $25 \mathrm{mM}$ $\mathrm{NaOH}-50 \mathrm{mM}$ MES, pH 6.3; $25 \mathrm{mM}$ $\mathrm{NaOH}-50 \mathrm{mM}$ MOPS, pH $7.2 ; 40 \mathrm{mM}$ tris-40 $\mathrm{mM}$ tricine, $\mathrm{pH} 8.1 ; 50 \mathrm{mM}$ morpholine-25 mM AcOH, pH 8.7; $50 \mathrm{mM}$ 2-amino2-methyl-1-propanol-25 mM AcOH, pH 9.8; voltage $-20 \mathrm{kV}$; current, as indicated in the figure; sample, a mixture of the IOPs in water, $\quad 0.05-0.5 \mathrm{mg} / \mathrm{mL}$ each; injection $10 \mathrm{mbar}, 10 \mathrm{~s}$; detection, UV at $206 \mathrm{~nm}$; temperature, $25^{\circ} \mathrm{C}$. Peak identification: 2 YD; 3, YDP; 4, YDPA; 5-10, YDPA(P) ${ }_{1}-\mathrm{YD}-$ $\mathrm{PA}(\mathrm{P})_{6}$. effective mobility, the lower the system zone mobility. It implies that CABCE electropherograms of moderately mobile ions are not affected by huge quantity but low mobility system zones induced by heterogeneity of the CAs. The same conclusion was earlier reported in the context of a model protein mixture analysis by CABCE at neutral or slightly alkaline $\mathrm{pH}$ in a bare fused silica capillary [12]. Indeed, in this previously reported work, no system peaks, in addition to the water dip detected at a migration time corresponding to that of the EOF, were observed. Since CE of very slow ions is in general not preferred and not frequently performed, the slow system zones of CAs do not seem to be a serious problem in most practical CABCE separations.
In general, important parameters for evaluation of system zones in CABCE are $\mathrm{pH}$ interval of the CA cuts used as BGE and a slope of the electrophoretic mobility $\mathrm{pH}$ dependence in the proximity of isoelectric point of the CAs. If $\mathrm{p} I$ of some CA constituent was remarkably different from intrinsic $\mathrm{pH}$ of the CA-based BGE, then effective mobility of this particular CA constituent of the BGE could also be remarkable assuming that its mobility $\mathrm{pH}$ dependence is steep. This may happen when $\mathrm{pH}$ interval, from which CAs are collected into one BGE, is relatively broad. Thus, mobile CAs constituents would induce system zones possibly fast enough to interfere with the analytes. Similarly, the presence of a moderate to fast mobility ion in the CA-based BGE can induce a system zone that could interfere with the 
Table 3. Separation of a series of nine IOPs in the CA-based BGEs

\begin{tabular}{|c|c|c|c|}
\hline $\begin{array}{l}\text { pH cut } \\
\text { no. }\end{array}$ & $\mathrm{pH}$ & $\begin{array}{l}\text { Minimum } \\
\text { resolution }\end{array}$ & $\begin{array}{l}\text { Average } \\
\text { resolution }\end{array}$ \\
\hline 13 & 5.2 & 0.35 & 2.23 \\
\hline 14 & 5.5 & 1.65 & 2.24 \\
\hline 15 & 5.8 & 1.32 & 2.01 \\
\hline 16 & 6.2 & 1.58 & 2.08 \\
\hline 17 & 6.7 & 1.78 & 2.51 \\
\hline 18 & 6.9 & 1.40 & 2.19 \\
\hline 19 & 7.1 & 1.23 & 1.90 \\
\hline 20 & 7.1 & 1.31 & 2.01 \\
\hline 21 & 7.3 & 0.96 & 1.66 \\
\hline 22 & 7.5 & 0.55 & 1.27 \\
\hline 23 & 7.9 & 1.12 & 1.64 \\
\hline 24 & 8.0 & 0.91 & 1.53 \\
\hline 25 & 8.3 & 0.98 & 1.64 \\
\hline 26 & 8.5 & 0.92 & 1.70 \\
\hline 27 & 8.8 & 1.43 & 2.08 \\
\hline 28 & 8.9 & 1.93 & 2.40 \\
\hline 29 & 9.1 & 1.99 & 2.44 \\
\hline
\end{tabular}

analytes. Example of such additional ions can be $\mathrm{H}_{3} \mathrm{O}^{+}$and $\mathrm{OH}^{-}$in the acidic and alkaline BGEs, respectively, or carbonate anions due to absorption of atmospheric $\mathrm{CO}_{2}$ in alkaline BGEs. A zig-zag baseline pattern at migration time of ca. 2 min in the traces of alkaline CA fractions in Fig. 3 is a system zone most likely due to presence of carbonates in the BGEs.

Peakmaster simulation of CA-based BGEs provides also a clue of electromigration dispersion of the analyte peaks. Basically, fast ions are more prone to peak triangulation than low mobility ions. This fact can be clearly evidenced by dispersed peak of short dipeptide YD in Fig. 3 as compared with more symmetrical peaks of less mobile larger peptides.

\section{Concluding remarks}

To summarize, separation efficiency of CABCE measured by peak resolution turned out to be as good as for $\mathrm{CE}$ in the classical buffers. The expected advantage of CABCE coming from low conductivity was not so evident at least for peptides and peptide mimetics. Presumably, the cooling system of commercial CE apparatuses is powerful enough to dissipate Joule heating generated in moderately concentrated BGEs such as the $25 \mathrm{mM}$ ionic strength used herein. Conversely, CABCE dominated in protein separations in which high ionic strength of the BGE was required $[9,12]$.

Further, in spite of numerous species contained in the narrow $\mathrm{pH}$ CA cuts almost no significant system zones are generated, which could hamper the CABCE analysis. The system zone observed in alkaline $\mathrm{pH}$ was presumably
Table 4. Separation of a series of nine IOPs in the classical saltbased BGEs

\begin{tabular}{llll}
\hline BGE & $\mathrm{pH}$ & $\begin{array}{l}\text { Minimum } \\
\text { resolution }\end{array}$ & $\begin{array}{l}\text { Average } \\
\text { resolution }\end{array}$ \\
\hline $25 \mathrm{mM} \mathrm{NaOH}-50 \mathrm{mM}$ MES & 6.3 & 2.18 & 3.40 \\
$25 \mathrm{mM} \mathrm{NaOH}-50 \mathrm{mM}$ MOPS & 7.2 & 1.40 & 2.48 \\
$40 \mathrm{mM}$ tris-40 mM tricine & 8.1 & 2.05 & 2.81 \\
$25 \mathrm{mM} \mathrm{AcOH-50} \mathrm{mM} \mathrm{morpholine}$ & 8.7 & 1.59 & 2.35 \\
25 mM AcOH-50 mM 2-amino- & 9.8 & 1.11 & 1.52 \\
$\quad$ 2-methyl-1-propanol (AMP) & & & \\
\hline
\end{tabular}

the consequence of the presence of carbonates in the BGE and therefore CA cuts cannot be blamed. As for electromigration dispersion, it turned out that peak distortion took place mainly for short peptides of rather high mobility whereas the zone of less mobile peptides remained symmetrical.

This evaluation of CABCE was performed mainly using acidic (anionic) peptides and peptide mimetics in majority of narrow $\mathrm{pH}$ cuts prepared by fractionation of Servalyt 4-9. Nevertheless, we believe that the results on peak efficiency, system zones and peak symmetry are valid for cationic analytes as well. All in all, it seems that CABCE is best suited for the separation of moderately to low mobility analytes such as proteins, i.e. for the same analytes for which CAs have been used in IEF for several decades. CABCE can be competitive in applications that require high ionic strength of the BGE and/or the experimental setup does not allow for efficient dissipation of Joule heating. Acceleration of the analysis time is the second major benefit of CABCE which, however, cannot be fully developed in commercial CE apparatuses. Systems allowing application of electric field strength greater than typical $30 \mathrm{kV}$ over the $25-30 \mathrm{~cm}$ long capillary would be best suited to get the most out of CABCE.

The work was supported by the Grant Agency of the Czech Republic, grant nos. 203/06/1044, 203/06/1272, 203/08/1428, by the Research Project Z40550506 of the Academy of Sciences of the Czech Republic, and by the project no. 13 of the cooperation between ASCR and CNRS in the years 2007-2008.

The authors declare no conflict of interest.

\section{References}

[1] Hjertén, S., Valtcheva, L., Elenbring, K., Liao, J. L., Electrophoresis 1995, 16, 584-594.

[2] Righetti, P. G., Gelfi, C., Bossi, A., Olivieri, E. et al., Electrophoresis 2000, 21, 4046-4053.

[3] Rilbe, H., Ann. N. Y. Acad. Sci. 1973, 209, 11-22.

[4] Righetti, P. G., Electrophoresis 2006, 27, 923-938.

[5] Vesterberg, O., Acta Chem. Scand. 1969, 23, 2653-2666. 
[6] Lalwani, S., Vigh, G., Electrophoresis 2005, 26, 3-9.

[7] Lalwani, S., Tutu, E., Vigh, G., Electrophoresis 2005, 26, 2047-2055.

[8] Rodemann, T., Johns, C., Yang, W. S., Haddad, P. R., Macka, M., Anal. Chem. 2005, 77, 120-125.

[9] Antonioli, P., Mendieta, M. E., Sebastiano, R., Citterio, A. et al., J. Chromatogr. B 2006, 833, 19-25.

[10] Busnel, J. M., Hennion, M. C., Peltre, G., J. Chromatogr. B 2005, 818, 99-107.

[11] Righetti, P. G., Isoelectric Focusing: Theory, Methodology And Applications. Elsevier Biomedical Press, Amsterdam 1983.

[12] Busnel, J. M., Kilár, F., Kašička, V., Descroix, S. et al., J. Chromatogr. A 2005, 1087, 183-188.

[13] Righetti, P. G., Simó, C., Sebastiano, R., Citterio, A., Electrophoresis 2007, 28, 3799-3810.

[14] Simó, C., Citterio, A., Righetti, P. G., Electrophoresis 2007, 28, 3156-3162.

[15] Busnel, J. M., Descroix, S., Godfrin, D., Hennion, M. C., Peltre, G., Electrophoresis 2006, 27, 563-571.

[16] Busnel, J. M., Descroix, S., Le Saux, T., Terabe, S. et al., Electrophoresis 2006, 27, 1481-1488.

[17] Busnel, J. M., Lion, N., Girault, H. H., Anal. Chem. 2007, 79, 5949-5955.

[18] Busnel, J. M., Descroix, S., Godfrin, D., Hennion, M. C. et al., Electrophoresis 2006, 27, 3591-3598.

[19] Collinsová, M., Castro, C., Garrow, T. A., Yiotakis, A. et al., Chem. Biol. 2003, 10, 113-122.

[20] Koval, D., Kašička, V., Jiráček, J., Collinsová, M., Garrow, T. A., Electrophoresis 2002, 23, 215-222.

[21] Koval, D., Kašička, V., Jiráček, J., Collinsová, M., Garrow, T. A., J. Chromatogr. B 2002, 770, 145-154.
[22] Koval, D., Kašička, V., Jiráček, J., Collinsová, M., Electrophoresis 2006, 27, 4648-4657.

[23] Koval, D., Kašička, V., Jiráček, J., Collinsová, M., J. Sep. Sci. 2003, 26, 653-660.

[24] Hlaváček, J., Tykva, R., Bennettová, B., Barth, T., Bioorg Chem. 1998, 26, 131-140.

[25] Hlaváček, J., Buděšínskỳ, M., Bennettova, B., Mařík, J. Tykva, R., Bioorg. Chem. 2001, 29, 282-292.

[26] Hlaváček, J., Bennettová, B., Barth, T., Tykva, R., J. Pept Res. 1997, 50, 153-158.

[27] Šolínová, V., Kašička, V., Koval, D., Hlaváček, J. Electrophoresis 2004, 25, 2299-2308.

[28] Rocco, A., Aturki, Z., D'Orazio, G., Fanali, S. et al., Electrophoresis 2007, 28, 1689-1695.

[29] Yiotakis, A., Vassiliou, S., Jiráček, J., Dive, V., J. Org. Chem. 1996, 61, 6601-6605.

[30] Kašička, V., Prusík, Z., Sázelová, P., Brynda, E., Stejskal, J., Electrophoresis 1999, 20, 2484-2492.

[31] Shen, Y. F., Smith, R. D., J. Microcolumn. Sep. 2000, 12, 135-141.

[32] Koval, D., Kašička, V., Zusková, I., Electrophoresis 2005 , 26, 3221-3231.

[33] Evenhuis, C. J., Hruška, V., Guijt, R. M., Macka, M. et al., Electrophoresis 2007, 28, 3759-3766.

[34] Štědrỳ, M., Jaroš, M., Gaš, B., J. Chromatogr. A 2002 960, 187-198.

[35] Štědrỳ, M., Jaroš, M., Včeláková, K., Gaš, B., Electrophoresis 2003, 24, 536-547.

[36] Štědrỳ, M., Jaroš, M., Hruška, V., Gaš, B., Electrophoresis 2004, 25, 3071-3079.

[37] Jaroš, M., Hruška V., Štědrỳ, M., Zusková, I., Gaš, B. Electrophoresis 2004, 25, 3080-3085. 